Article

\title{
Ethnic and Racial Identity in Multiracial Sansei: Intergenerational Effects of the World War II Mass Incarceration of Japanese Americans ${ }^{1}$
}

\author{
Karen L. Suyemoto \\ College of Liberal Arts, University of Massachusetts Boston, 100 William T Morrissey Blvd, \\ Boston, MA 02125, USA; karen.suyemoto@umb.edu
}

Received: 14 June 2018; Accepted: 25 July 2018; Published: 6 August 2018

\begin{abstract}
This paper reflects on ways in which intergenerational familial experience of the Japanese American World War II mass incarceration may have differentially affected the ethnic and racial identity development of multiracial Sansei (third generation Japanese Americans). I begin with a brief review of the literature related to the effects of the camps on Nisei, integrating psychological understandings of racial and ethnic identity development, contextual history, and research on the psychological effects; I focus here on effects for Nisei that have been connected to their intergenerational interactions: distancing from Japanese American heritage and identity, silence about the camp experience, and the negotiation of racism and discrimination. I turn then to the primary focus of the paper: Using a combination of autoethnographical reflection, examples from qualitative interviews, and literature review, I engage in reflective exploration of two ways in which intergenerational effects of the camp experience influenced Sansei racial and ethnic identities that vary among monoracial and multiracial Sansei: familial transmission of Japanese American culture by Nisei to Sansei, and the intergenerational effects and transmission of racial discrimination and racial acceptance. I conclude with reflections on intergenerational healing within Japanese American families and communities, and reflections on the relation of these dynamics to current issues of racial justice more generally.
\end{abstract}

Keywords: multiracial; identity; Nisei; Sansei; intergenerational trauma; communication; Japanese American; internment; World War II; incarceration

\section{Introduction}

The WWII Japanese American mass incarceration is often seen as the defining event in terms of cultural, group, and personal views of what it means to be Japanese in the United States, especially for

1 There is continued controversy about the language used to describe the camp experience during W.W.II. (see Hirabayashi 2008; Lee 2015; Schumacher-Matos and Grisham 2012) Although "internment" or "relocation" are often used, these are technically incorrect and I agree with other authors that argue that these terms fail to capture either the intent or the effect (see Daniels 1991; Japanese American Citizen's League 2015; Lee 2015). "Relocation" is not appropriate, as relocation means changing areas and resettling-it does not mean being placed behind barbed wire with armed guards at the exits. "Internment" is also problematic, as it refers to "a well defined legal process by which enemy nationals are placed in confinement in times of war" (Daniels 1991, p. 6). Daniels notes that the incarceration of Japanese immigrants and non-U.S. citizens immediately after Pearl Harbor was internment but the imprisonment of almost 100,000 U.S. citizens because of how they looked and because of a more powerful group's desire for economic gain does not fit the definition of internment. The use of "concentration camp", endorsed by the JACL and initially by the Japanese American National Museum, is technically accurate as the term used to confine people on the basis of political affiliation, race, or ethnicity (Japanese American Citizen's League 2015). The term concentration camp is also one that was used at the time (Japanese American National Museum n.d.), including by United States (U.S.) officials such as President Franklin D. Roosevelt, although the government changed its public language in order to make the camps more acceptable: 
the Nisei, second generation—or first American born—Japanese Americans (Daniels 1991; Kitano 1993; Nakanishi 1993). ${ }^{2}$ Over 120,000 people of Japanese heritage were imprisoned in camps based on racism, two-thirds of them United States (U.S.) citizens. Although the camps closed almost three-quarters of a century ago, the psychological, familial, and social legacies continue. The nature of those effects, however, varies, depending on one's own personal and familial positionality in relation to those historical events as well as in relation to current related events (e.g., Muslim bans). One area of continued intergenerational effect is in the racial and ethnic identity development of third generation Japanese Americans (Sansei), who were, for the most part, not actually imprisoned in the camps.

Ethnicity encompasses the culture that is shared by a group with a common history and geography, which may involve language, social connections, norms, and traditions; as a type of culture, ethnicity involves meanings (values, beliefs, behaviors) that are shared and transmitted amongst an identified group (Chang and Kwan 2009; Phinney and Ong 2007; Suyemoto 2002). Ethnic identity is the personalization of the ethnocultural heritage(s) or experience, which is often depicted as developmental models of exploration, affiliation, and commitment to values and relational connection and belonging (e.g., Phinney and Ong 2007; Chang and Kwan 2009). For Japanese Americans, as with other Asian Americans, ethnic identity often means negotiating the processes of enculturation and acculturation (Kim 2009) navigating differences between Japanese or Japanese American ethnicity (e.g., face, stoicism, collectivism, harmony; e.g., see overviews in Uba 1994; Sue and Sue 2015) and the dominant European American ethnicity of the United States (e.g., individualism, assertiveness, independence).

Racial identity refers to the development of identity related to experiencing the social consequences of a racialized world view (Smedley and Smedley 2005), which for people of color involves negotiating experiences of racism and stereotyping as well as experiences of belonging to and affinity with others who have had similar social experiences based on similar racial categorization (Suyemoto 2002). Racial identity is also often modeled as a developmental process, one of becoming aware of racial distinctions and racism, negotiating pressures to internalize the denigration of racial minority groups (including one's own), and developing empowerment and resilience through positive attitudes and affiliation (see Chang and Kwan 2009 for an overview of ethnic and racial identity for Asian Americans). Racial identity for Japanese Americans, as for other Asian Americans, often entails negotiating personal and historical experiences of racism, including perpetual foreigner stereotype, the imposition of the model minority myth, invisibility, and the denial of racial reality (Sue et al. 2007; Tsuda 2014). For Japanese Americans, specifically, it also entails negotiating legacies of the mass incarceration camp experience, especially for Japanese Americans whose families were living in the U.S. during WWII.

Ethnic and racial identity development are not individual experiences, but are instead social processes, emphasizing shared cultural experiences and traditions and social experiences of acceptance, rejection, and identification (Markus 2008; Maykovich 1972; Poston 1990; Stephan 1992; Shih et al. 2007; Suyemoto 2002). They centrally involve the negotiation of shared meanings of ethnic culture and of racialization, both of which are socialized. As social processes or constructions, ethnic and racial identity are strongly affected by the family and familial socialization. Thus, the ways in which the Nisei did or did not transmit ethnic culture and values and did or did not address the racial dynamics of the

Supreme Court Justice Owen J. Roberts declared on 18 December 1944, “An 'assembly center' was a euphemism for a prison ... so-called 'relocation centers,' a euphemism for concentration camps". The detention orders were called "civilian exclusion orders," and American citizens were referred to as "non-aliens." (Japanese American National Museum 1994).

However, "concentration camp" is controversial because of the links to the Nazi death camps; clearly the U.S. concentration camps were not death camps. In general, I use the terms "mass incarceration", and "incarceration camps" or simply "camps", although occasionally I use the term "concentration camps" with the meaning of explicit distinction from death camps.

2 Japanese Americans count generations starting from the immigration from Japan. Thus, the first generation (Issei) were immigrants from Japan, their children are the second generation (Nisei) who are the first American born generation. This can be confusing if one is used to defining the "first generation" to mean the first American born generation, rather than the immigrant generation. 
camp experience affected the ethnic and racial identity development of their Sansei children. As social processes, ethnic and racial identity are also affected by experiences of belonging and exclusion from both the ingroup (e.g., Japanese Americans) and the outgroup (e.g., the European American group), and by the power and privilege differences between these groups (e.g., see Ancheta 2006; Tsuda 2014). Finally, ethnic and racial identity are affected by larger societal and historical events, especially those that are closely tied to issues of race and ethnicity, such as the World War II incarceration camps.

This paper examines these effects, and it particularly considers the ways in which these effects might vary for multiracial Sansei, given the ways that ethnocultural transmission and racial discrimination are differentially experienced in relation to the dominant European American community as well as in relation to the Japanese and Asian American communities and their attitudes towards multiracial Asian Americans. I am seeking here to explore connections between the individual, the familial, the group, and the social-structural; to connect historical events with current lived experience through tracing familial and community psychological dynamics. I begin with a brief review of the literature related to the effects of the camps on monoracial Nisei racial and ethnic identities, integrating psychological understandings of racial and ethnic identity development, contextual history, and prior research on the psychological effects of the camps for Nisei. I turn then to the primary focus of the paper: the ways in which intergenerational effects of the camp experience influenced the racial and ethnic identities of monoracial and multiracial Sansei. I discuss effects of the camp experience on familial transmission of Japanese American culture and the intergenerational effects and transmission of racial discrimination and racial acceptance, with a focus on the established Nisei silence and experiences of racism and exclusion, not only by the dominant White American group, but also (for multiracial Sansei) by the Japanese American group, and, in some cases, from either or both sides of their extended families. I conclude with reflections on intergenerational healing within Japanese American families and Japanese American communities, and reflections on the relation of these dynamics to current issues of racial justice in the United States.

To support and illustrate the central effect themes, I include personal narrative drawing from an autoethnographical approach to begin each section on multiracial experiences; these reflections are presented in italics. In the subsequent exploration of multiracial experiences related to cultural transmission and racial discrimination, I include additional illustrative examples from themes and quotes in interviews we conducted with multiracial Sansei in the late 1990s. Interview participants included four female and two male multiracial Sansei (five of European-Japanese American heritage and one of African-Japanese American heritage). Interviewees ranged in age from 26 to 49, with a mean age of 34. Participants were recruited through Japanese American and mixed race newsletters associated with groups centered in the San Francisco Bay area, and through word of mouth using the snowballing technique. All of the participants lived, worked, or went to school in the Bay area at the time of the interviews, although their demographic backgrounds were more geographically varied. The interviews were unstructured; they began with asking participants to describe a bit about themselves and their background, and to discuss how they currently identified in terms of ethnicity/culture/race. Participants were asked about their familial experience and exposure to information about the Japanese American WWII imprisonment and about how this experience and knowledge affected their ethnic and racial identities. Half of the six multiracial interviewees had familial experience with the internment (i.e., their Nisei parents were interned) and half did not, although all of the Nisei parents lived on the mainland. However, all six participants discussed ways in which the internment and the racial hysteria of that time affected their Nisei parents and their families. Their responses indicated that aftereffects discussed in imprisoned Nisei (distancing from Japanese heritage, desire for their children to assimilate, desire to be perceived as truly American, etc.) apply to mainland Nisei who were not imprisoned and yet had to deal with the social climate of that time and place. One must remember, however, that the experiences of each individual Nisei and Sansei are very diverse, not only between those who had direct familial experience with the internment and those who did not but also within each group. For example, one of the most salient 
variables affecting identity and the effects of the internment camps in monoracial and multiracial Sansei may be geographical location and whether there was a Japanese American community and other Japanese American and/or multiracial individuals in the developmental (childhood and adolescent) lives of Sansei; this agrees with Nagata's (1993) findings that East coast and Californian Sansei differ in their reactions to the internment as well as Mass's (1992) findings that location and community affect self-concept development in multiracial Japanese Americans. As this example demonstrates, many variables other than mono- vs multiracial familial composition can create differences between groups as well as within groups.

The exploration here reflects a particular historical context. My primary focus is on Sansei born after the war and the incarceration, rather than the smaller group of Sansei who were born before or during the camp experience. Most Sansei belong to the baby boomer generation, or the early years of "generation $x$ ". Their Nisei parents were children, adolescents, or young adults during WWII ("Nisei" 2013), and therefore most likely first married sometime in the 1940s to 1960s; Interracial marriage was far less common or accepted prior to the Loving decision in 1967, and tensions between Japanese Americans and White Americans continued to be high following the war; thus, the Nisei and their non-Japanese spouses who intermarried at that time likely encountered resistance and discrimination from both the White European American dominant society, as well as from within the Japanese American, Asian American, and/or other racial minority communities. This discrimination may have been experienced within the Japanese American family as well. The Sansei examples in this article are referencing developmental experiences from the 1960s through the late 1990s. These experiences mostly took place prior to passage of reparations (Civil Liberties Act of 1988); the movement to obtain redress and the passage of the Civil Liberties Act of 1988 changed the nature of Japanese American familial and community discourse about the camp experience, increasing Nisei willingness to discuss the camp experience (Nagata and Cheng 2003). In addition to the familial and intergenerational cultural, racial, and camp related experiences that are discussed here, Sansei ethnic and racial identities would also have been shaped by the historical movements for redress and, more generally, for civil rights and ethnic studies.

\section{Effects of the Camp Experience for Nisei's Ethnic and Racial Identity}

The Nisei were born at a time when their parents were ineligible for U.S. naturalization and citizenship due to Asian exclusion laws (Ancheta 2006). The Nisei were therefore the first "hyphenated" generation (although we no longer use hyphens): they were Japanese Americans. Most Nisei identified as American, not only in their nationality, but also in much of their culture (Maykovich 1972). They were far more acculturated than their Issei parents: they grew up with American language (English), American (meaning European American) education, American music and social activities, and many American values. However, it is also clear that the Nisei identified culturally as Japanese Americans: many Nisei attended Japanese language schools, spoke Japanese at home, and experienced the transmission of Japanese values, communication styles, and other aspects of Japanese cultural heritage from the Issei, especially prior to WWII (Kitano 1993; Maykovich 1972).

Both parts of the Nisei's ethnic and racial identity had contested aspects, even prior to WWII. In terms of their identification as Japanese Americans, acculturation and forces of the dominant White American social context led them away from the kind of clear identification with Japanese culture that their parents had had, contributing to a potential cultural disconnection (Maykovich 1972). This process of acculturation and assimilation, with associated stress and intergenerational conflict and distance, was similar to that of other immigrant communities (e.g., see Chung 2001; Uba 1994, and overview in Kim 2009). The Nisei's identification as Japanese American was even more contested; although they were American citizens and therefore legally uncontested in their American national identity, the Nisei were not accepted by the American dominant social context, due to racial discrimination (Kitano 1993; Mass 1991; Takaki 1998). The rejection of the Nisei's American identity was not based on nationality, or even primarily on culture. Regardless of how acculturated the Nisei were, they were still a visible 
minority, an issue that continues even with today's Yonsei, Gosei, and beyond (Tsuda 2014). In spite of not being accepted as American by White European Americans, the Nisei continued to identify as American before the war, expecting the rights of American citizens, having been schooled in American values of equality, democracy, and Constitutional rights (Mass 1991; Nagata 1990), and sometimes seeking to be an exemplar of racial bridges and harmony (Austin 2007).

When the possibility of evacuation and imprisonment arose after Pearl Harbor, many Nisei hoped that the order would not apply to them; they not only identified as Americans culturally but also were legally American citizens (Kitano 1993; Nagata 1990). To include the Nisei meant the movement from "internment" (applied to enemy nationals who are non-citizens) to "concentration camps"meaning camps that are based on political, racial, or ethnic affiliation—an affront to the U.S. values in which the Nisei had been schooled. The war and the camp experience therefore significantly further problematized the Nisei's ethnic and racial identity process. The inclusion of the Nisei in the evacuation order made it explicitly clear that, regardless of legal citizenship or national identity, shared American cultural experiences, and claimed ethnic identity, the dominant White American social structure rejected the Nisei identification as American. However, in spite of the initial and continued explicit rejection of the Nisei's claimed American identity by White Americans, most Nisei continued to identify and attempt to explicitly portray their identification as American both during and after the war. In fact, many authors have noted the Nisei's reactive attempt to emphasize their American values and identity during and after the camps, and de-emphasize their Japanese cultural heritage (Kitano 1993; Morishima 1982; Nagata 1991, 1993; Nagata et al. 2015; Tomine 1991). Mass (1991, p. 161) states "By trying to prove we were 110 percent American, we hoped to be accepted" and Miyoshi echoes: "It was safer to emphasize their Americanism and even deny their Japanese identification in the racist clime of their surroundings" (Miyoshi 1978, p. 4). Simultaneously, the camps created an intense ethnic enclave, with decreased exposure to European American people and lived culture, and increased salience of Japanese culture, ethnicity, and race.

Racial discrimination, marginalization, and exclusion continued after the war as well, even as assimilation was encouraged by the U.S. government policies and various organizations that promoted resettlement, dispersal, and assimilation (Austin 2007). Some Nisei accepted government propaganda and sought to assimilate in hope that they might be accepted as individuals, rather than seen as a group (Austin 2007). However, many Nisei alternatively or simultaneously continued to identify with and value their Japanese cultural heritage (Austin 2007; Kitano and Daniels 2000; Maykovich 1972; Takaki 1998). The majority of Japanese Americans returned to the west coast after the camps and rebuilt their ethnic communities. As the Issei died, Nisei maintained a Japanese American community with community events, organizations, and activities (Kitano 1993; Kitano and Daniels 2000; O'Brien and Fugita 1991). Nisei also maintained many of the Japanese American values important to their parents, as well as the Japanese high-context, nonverbal communication style (Kitano and Daniels 2000; Miyoshi 1978; Tomine 1991; Uba 1994) ${ }^{3}$, although these values were frequently not explicitly recognized or articulated in their attempt to identify as American. Tomine (1991, p. 94.) states that although the Nisei participants in her study rated themselves as very American and denied the impact of Japanese culture, they were often surprised by how Japanese they were when they began talking about Japanese values and coping styles; "the unconscious influence of Japanese culture on the Nisei personality is more prominent than may be outwardly acknowledged." The personal and cultural ambivalence about Nisei's Japanese American ethnicity raises questions about how ethnocultural socialization was enacted with the Sansei.

3 For a more general discussion of high context communication and its relation to cultural values and characteristics, see (Hall 1976; Sue and Sue 2015; Ting-Toomey 1989). 
Unsurprisingly, the camps had negative effects for Nisei mental health and well-being (Mass 1991). Even decades later, Nagata and Tsuru (2007) found that Nisei continued to be affected by the camp experience, concluding:

These findings are sobering in that they reflect a lingering sense of internment-related tension in the lives of former internees more than 50 years after incarceration. Despite outward appearances of adjustment, it is clear that some Nisei continue to carry a psychological burden from their past. (p. 227)

Of specific relevance to intergenerational transmission and identity, Nagata et al. (2015) argue that the camp experience was a cultural trauma for Japanese Americans that "changed their future identity" (p. 359), particularly because of the virulence of the underlying racism. A central response to this trauma that strongly affected intergenerational relationships with their Sansei children was silence. It is well documented that Nisei rarely discussed their camp experience, especially prior to the reparations movement (Daniels 1991; Kitano 1993; Kitano and Daniels 2000; Miyoshi 1978; Nagata 1990, 1991, 1993, 1998; Nakanishi 1993; Tomine 1991). While the camp experience may have been referred to as a time marker ("before camp", after camp"; Nagata 1990) the full descriptive and emotional story was rarely told, even to their children. The possible reasons for this silence are many: a desire to protect their children from the discrimination and pain that they experienced and allow for them (Sansei) to more fully integrate (Miyoshi 1978; Nagata 1990, 1998; Nakanishi 1993; Nagata et al. 2015); a fear of discrimination or ostracism from others (Kitano 1993); a fear of becoming emotional in front of others (Miyoshi 1978); the desire to not lose face by complaining or losing admiration for endurance (Miyoshi 1978); or a sense of shame that has been analogized to the experience of rape victims (Mass 1991; Nagata 1990; Nakanishi 1993; Tomine 1991). The silence regarding the camps in the dominant American discourse was also externally reinforced (Tomine 1991). Familial silence about cultural trauma is not specific to Japanese Americans, but has also been described among Jewish Holocaust, Cambodian genocide, and Armenian genocide survivors (see, e.g., Lin and Suyemoto 2016; Miller and Miller 1993; Pennebaker et al. 1989). Some of this literature indicates that silence does not actually protect the children but may, itself, communicate distress (e.g., Lin and Suyemoto 2016).

Regardless of the intention, silence affects the ethnic and racial identity process of the Nisei and the intergenerational dynamics with Sansei children because a major contributor to Nisei ethnic and racial understanding was concealed. Furthermore, because the silence relates to the distancing and denial of Japanese heritage and Japanese American history and experience (Miyoshi 1978; Nagata 1990, 1993; Nagata et al. 2015), it potentially contributes to Sansei challenges in naming, understanding, and relating to their Japanese and Japanese American ethnocultural heritage, as well as the challenges in negotiating the historical legacy and current experiences of racism and discrimination.

\section{Ethnic and Racial Identity in Monoracial and Multiracial Sansei: Intergenerational Legacies of the Camps}

This, then, was the personal, familial, and historical context for Sansei ethnic and racial identity development. The Sansei's ethnic and racial identity development was characterized by being overtly pushed toward American cultural identity and covertly pulled towards Japanese cultural identity by their Nisei parents and by the dominant American cultural messages of assimilation and marginalization. The dominant American social context communicated messages about the greater worth of White American values, worldview, and identity and the simultaneous rejection of Sansei as belonging to this group and identity due to racial categorization and discrimination. While the camp experience is not the sole contributor to this dynamic, it accelerated the processes of acculturation in both Nisei and Sansei while simultaneously intensifying and making explicit racial discrimination and exclusion. The ways in which Nisei did or did not pass on their cultural heritage and experiences and lessons from racial exclusions were affected by the camps in ways that are applicable to both monoracial and multiracial Sansei. However, for multiracial Sansei, these issues may be further complicated by several uniquely experienced factors, including further distancing from the Japanese 
heritage related to outmarriage; either decreased or increased access to communication and naming of Japanese culture, values, and camp experiences resulting from one parent being non-Japanese: and particular types of racialized discrimination and rejection from the dominant White community, as well as from the Japanese American community and the extended family. Below, I present two areas of effects of the camps on Sansei racial and ethnic identity: transmission of cultural heritage and negotiating racial discrimination. I then explore the differential experiences of multiracial Sansei in relation to these areas.

\subsection{Transmission of Cultural Heritage, Addressing Racial Discrimination, and Intergenerational Effects of the Camps Affecting Ethnic and Racial Identity in Sansei}

I present here a brief review of issues that are related to Sansei experiences of transmission of cultural heritage, racial discrimination, and intergenerational effects of the camps, as discussed in the literature. However, most of the established literature on intergenerational effects of the camps between Nisei and Sansei does not specifically identify whether the Nisei discussed or included as participants in research were in within-race or interracial marriages or whether the Sansei discussed or included as participants were monoracial or multiracial. Instead, this literature speaks generally about Nisei and Sansei. Thus, it is difficult to determine whether or how the dynamics included in this literature are applicable to Sansei generally, or only to monoracial Sansei.

In terms of transmission of culture, although Nisei received relatively clear communication of their Japanese cultural heritage from their Issei parents, their relationship to that heritage was affected by the camp experience. The camps challenged Nisei's negotiation of their own ethnic and racial identity development and fostered ambivalent attitudes towards their Sansei children's ethnic and racial identity development (Miyoshi 1978). A legacy of the camp discrimination was that many Nisei attempted to encourage an American identity for their Sansei children rather than encourage Japanese related identity. However, Nisei simultaneously retained many Japanese values and cultural norms of which they were unaware as noted above and did transmit to their Sansei children many aspects of the Japanese cultural heritage, including values and coping styles (Kitano 1993; Kitano and Daniels 2000; Nagata 1993; Tomine 1991). However, due to Nisei's attempted distancing from their Japanese heritage, this transmission of values may not have been recognized or named as racial or ethnic socialization.

Furthermore, even the Nisei's intergenerational silence and approach to dealing with the camp experience may have been related to Japanese cultural norms. For example, the Japanese American stoicism and silence in response to the camp experience has itself been connected to Japanese values of gaman (psychological endurance with dignity), shikata ga nai (it cannot be helped, or the acceptance of what cannot be changed), honor, and saving face. Thus, although silence about trauma is a reaction not specific to Japanese culture, in the case of the camps the silence itself may be more culturally Japanese than American and may have cyclically reinforced the high-context, nonverbal style of communication that is more culturally Japanese (Miyoshi 1978).

Nisei may also have been less aware of whether or how their Sansei children were experiencing communication. Nagata and Cheng (2003) found that Nisei (surveyed after redress) reported much more communication about the camps than Sansei reported experiencing (surveyed before redress). Although some of this discrepancy is likely due to the passage of redress and its effect on increasing communication, Nagata and Cheng attributed part of this difference to a generational difference in the nature of communication, where Japanese American parents use more indirect or nonverbal approaches. Overall, the Nisei attempt at distancing from Japanese culture may have led to a lack of explicit naming and recognition of the Japanese foundation of many of the shared meanings (values, beliefs, behaviors) that were being transmitted to Sansei; simultaneously, the cultural norms were still being transmitted, perhaps even through the specific processes of silence and stoicism. It was the conscious unifying referent that was left out.

Sansei may therefore have been ethnically socialized with aspects of the Japanese worldview and culture without recognizing their cultural and historical foundations. These internalized, yet unnamed, 
aspects may have led Sansei to feel their cultural difference from White European Americans but to have had little referent or foundation to explain this, as expressed by this Sansei participant interviewed by Miyoshi:

A lot of things I didn't know were cultural values ... so it was helpful to identify them as possible things that were culturally derived ... You like to feel that your ethnic identity is actually a contributing factor in your own personal identity ... if you feel that it comes from your own cultural values, you feel completely different about it ... If you can identify those cultural things, it gives you some idea, some understanding of where your parents came from ... and if you have a part of that in you, it's not something terrible. It's something that was passed down to you. (Miyoshi 1978, p. 9).

In addition to effects that are related to ethnocultural transmission and socialization, the camps affected Nisei's approach to racialization and racism, and the ways in which they socialized their Sansei children or offered guidance in negotiating the historical legacy of the camps as racism. As noted above, in response to the racism and racial exclusion of the camps, Nisei frequently attempted to adopt a primarily American identification. They also often encouraged a primarily American identification in their children, in the hope that their children would not experience the same discrimination and exclusion that they did. But, the realization of an "American" ethnic and racial identity is impossible for Nisei or Sansei (or any Japanese American) as long as "American" means "White". (Miyoshi 1978; Tsuda 2014). Although Asian Americans may emphasize cultural affinities and identities, in the U.S., race is the primary categorization, as a master status (Ancheta 2006; Omi and Winant 1994; Suyemoto 2002). Similar to the Nisei experience, Sansei continue to be a visible minority despite their increased acculturation (Ancheta 2006; Kitano 1993; Kitano and Daniels 2000; Maykovich 1972; O’Brien and Fugita 1991; Tsuda 2014).

The historical experience of the camps is a reminder that the dominant social environment did not accept Japanese Americans as true Americans with associated rights. Knowledge of this experience, especially if it affected members of the immediate family, may have led Sansei to feel that it was particularly difficult to accept an American identification with White Americans (perhaps seen as historical and/or familial oppressors) as the sole or primary referent group (Nagata 1991). Nisei silence about the camps may have made it even more difficult for Sansei to discuss and to come to terms with the personal and familial impact of this oppressive experience and its meaning for Sansei's ethnic and racial identity process Miyoshi 1978; Tomine 1991). The dynamics of race in the U.S. and the personal, familial, and social legacy of the camps make an American identity both desirable and impossible. However, a Japanese American identity is more approachable for monoracial Sansei.

\subsection{Transmission of Cultural Heritage and Ethnic and Racial Identity in Multiracial Sansei}

I grew up in New England, in a suburb of Boston. My father is Nisei and was in Topaz in his early adolescence. My mother is White European American, from a poor, rural, southern Baptist background. I don't remember when or how I learned about the camps. It seems I've always known the facts, but only as a distant historical thing, not a reality with emotions and current effects behind it. When I was in high school my father came to my history class to talk about Topaz-how many Japanese Americans were interned, the government rationale, how Topaz looked and was laid out, what the food was like (bad), and how the weather was (worse). But there was little that was personal in this presentation, or in the rare discussion at home. I had no sense of what the internment really meant; how it affected him or his family in terms of feelings, relationships, hopes, or dreams; or how it shaped who my father was as an individual, as a Japanese American, or as a father.

It was not until I was in graduate school and started asking detailed and explicit questions within the frame of class assignments about culture and family therapy that I began to learn how the camp experience had affected him. Eventually, my father could reflect on how after the camps he had made a deliberate effort to distance himself from being Japanese American and from the Japanese American community, from Japanese values and traditions, from certain family attitudes and expectations that were rooted in Japanese worldviews. He didn't see 
himself as Japanese, or even as Japanese American-he didn't identify or name himself that way; he was just "American". When I eventually asked him about marrying out, I received the answer I both expected and feared: his outmarriage was related to a desire to have "American" children, with American values, American traditions, American language, American features and skin (White, or at least, Whiter). He didn't want a Japanese partner who not only might pass on her own Japanese influence, but also might increase his inadvertent passing on of his Japanese familial culture.

Looking back, I can see how these feelings and responses shaped his fathering and begin to understand how they have affected my own identity. Growing up, Japanese was not really defined -I was Japanese because my father was Japanese, because of the color of his/my skin or the shape of his/my eyes, because this atrocity called the "internment" had happened sometime in my family history. But what it meant to be Japanese was a mystery. Nothing was named Japanese, and the Japanese culture was never a referent. But there was a sense of being different, of having some things mean more to me than to my White peers, of knowing some things were Right or Wrong (always with capitals in my mind) that others didn't seem to worry about. It was with considerable relief that I began to learn as an adult that these things had a cultural base, that these were concepts rooted in history and a collective people with particular and important meaning, that these concepts could be named with words with cultural meanings—words like "face", "honor", shame, "giri (reciprocal obligation)", "enryo (modesty in the presence of superiors), and "gaman" (endurance and perseverance with dignity)".

Multiracial Asian Americans seem to identify most with being mixed or both, rather than following a pattern of hypodescent (where identity is assigned to the lower status racial background, such as multiracial Black Americans who negotiate legacies of the "one drop rule") or hyperdescent (where racial identity is assigned as White for White-racial minority multiracial individuals, such as some multiracial Native Americans), likely due to different historical trajectories and meanings (Gullickson and Morning 2011). This increases the salience of the continual negotiation of multiple race and ethnocultural contexts, rather than a single primary identity. For multiracial Japanese Americans with a family history in the camps, the negotiation of identity is related to the intersection of cultural silence and multiraciality.

For multiracial Sansei, the lack of recognition and naming of Japanese ethnic heritage from their Nisei parent may either be exacerbated or lessened when compared to monoracial Sansei. In some cases, as in my family, the Nisei parent's decision to outmarry may be explicitly related to a conscious or unconscious desire to distance even further from Japanese culture and values, and to emphasize American values and family style, catalyzed or exacerbated by experience of the camps. The distancing from Japanese culture and the lack of socialization noted by Miyoshi may then be exacerbated as well. Even if the decision to outmarry is not explicitly related to distance from either the culture or the camp experience, multiracial Sansei may experience more profound silence and distance from Japanese culture and heritage within the family. This may be caused by the simple fact that the parents are not both Japanese, decreasing the Sansei's access and experience with Japanese tradition. Even if the decision to outmarry was unconscious or not explicitly related to distancing, the Nisei parent may find it easier to distance with a non-Japanese spouse. Silence regarding the camps may be similarly exacerbated. This possibility is reflected in Nagata's $(1990,1993)$ work, where she found that Sansei whose parents had both been imprisoned had significantly more conversations with their parents about the camp experience than Sansei who had only one parent in the camps. This effect might be even more intense if one parent were not Japanese American and thus did not feel the familial or racial impact of the camp experience. Difficulty understanding the Nisei parents' nonverbal, high-context communication may be similarly affected, as having a non-Japanese parent who may rely more on verbal content-explicit communication may lead to less awareness of the process of nonverbal, high-context communication.

Some of our interview participants also discussed the lack of naming of Japanese culture and heritage, the distance from the culture as well as the Japanese American community, and the silence 
regarding the camp experience. Elizabeth ${ }^{4}$ stated: “I always knew that I was Japanese, but I didn't know what it meant. Later, she elaborated on how this related to cultural transmission:

My dad never really talked about this is Japanese and this is. So I don't really know what is or isn't. I mean I just found out that persimmons are something that the Japanese eat [and] grow. It's definitely a part of the Japanese culture or ethnic or whatever and I never [knew] that. He used to eat persimmons all the time, [but] he never said "oh yeah, well you know, this is something is that my parents blah blah blah or whatever." He refused to teach us Japanese language even though I asked on numerous occasions and he would make Japanese foods every once in a while, but I think that was just because he loves food and so that was something that he couldn't give up. But he gave up a lot. (Q: why do you think he chose to give so much?) I think it was social pressure.

Laura stated: “When I think back on my childhood, I'd thought of myself as being half Japanese, but that kind of had a different meaning at that point [in childhood]. I mean, I didn't exactly know what that meant to me."

Multiracial Sansei raised by a single, non-Japanese parent due to divorce or death may have even greater challenges with identity issues due to distance and non-recognition of the Japanese cultural heritage. Some of our interview participants fell into this category; while difficulties within the family were different (e.g., the Sansei child-Nisei parent communication clash between verbal and nonverbal communication became less relevant because the Japanese parent wasn't present), issues regarding identity and cultural heritage could be intensified (e.g., struggling with being racially identifiable as Japanese but having little sense of what that meant and no model from which to make inferences). Identity difficulties were further exacerbated in those multiracial Sansei raised by a non-Japanese parent, who, because of inter-family racism or prejudice, have little contact with their Japanese extended family and/or experience discrimination from their non-Japanese extended family (see below).

Alternatively, difficulties regarding recognition and naming of Japanese heritage and silence regarding the camp experience may be decreased for multiracial Sansei in interracial families. The non-Japanese parent may not be bound by the same cultural values of loyalty, duty, stoicism, and endurance; this parent may have less fear of discrimination and less need to show they are " $110 \%$ American"; they may feel comfortable being verbally explicit about sensitive emotional experiences and willing to share their knowledge about their Nisei spouse's camp experience with their Sansei children. In sum, the non-Japanese parent does not have the Japanese cultural norms and values and cultural trauma (Nagata and Cheng 2003; Nagata et al. 2015) from the camp experience that contributes to silence and intergenerational distance. Our interviewee Laura stated “... My mom, who is actually the European American one, has always been more the one that's presented the [camp] experience ... she's the one that's given me the more hard core version of internment". The non-Japanese parent may also actively encourage embracing Japanese culture and tradition and be willing and able to explicitly name those values and traditions with Japanese foundations, being able to more clearly recognize their Japanese referent because of the difference from their own non-Japanese experience. Some of our interviewees discussed how their non-Japanese parents would take the family lead to celebrate Japanese holidays, incorporate Japanese foods and traditions, and explicitly discuss Japanese cultural values.

4 My experience as a multiracial Sansei is also shaped by being in the Northeast, where the populations of both Japanese Americans and multiracial Asian Americans are less numerous than on the west coast. 


\subsection{Racial Acceptance, Racial Discrimination, and Racial Identity in Multiracial Sansei}

Growing up, I had no contact with the Japanese American community and, until college, I had no friends or acquaintances who were Japanese American (other than my relatives). It was not until graduate school that I met another multiracial Japanese American.

When I was very young, I don't think I really had an awareness of being Japanese or Asian, of being racially or culturally different from my White American peers. My friends and neighbors never said anything about my being different and the Japanese culture was not a referent in my house. Then, when I was about 8, I was chased home from school on the anniversary of Pearl Harbor day by a group of boys yelling "Jap." This was the first of many explicitly racist experiences, ranging from shouted racial slurs to comments on my exotic looks. Through these experiences, I came to identify as Japanese and as Asian, based on how others classified me and the discrimination I endured.

While some could identify me as Asian, a larger group had difficulty placing me, although they knew I was "something" (i.e., not White). This made identifying as Japanese American difficult. I was constantly reminded that I wasn't wholly Japanese and I didn't fit in to the American racial categories by the many people who asked "What are you?" Strangers in the grocery store would ask me this question, as well as acquaintances or new friends. And occasionally my identification as Japanese American would not even be accepted, as when one White woman retorted: "You can't be, you don't look Japanese." The "what are you?" question not only confronted me with the fact that I wasn't wholly Japanese and identifiable as Asian, but also with the fact that I wasn't seen as wholly American. At times I would answer "I'm American" or respond to "where do you come from?" by saying "Boston". But these responses would inevitably be met with "no, really, what are you?"

And there were other issues with identifying as Japanese American. One was the fact that my mother never acknowledged that I was racially different than she was. Even after many conversations we had after I began exploring my ethnic and racial identities, she would say things like "I'm so glad I moved away from that neighborhood and all those Asians." When I reminded her that I'm Asian, she responded "I don't think of you that way," as if that somehow made me White. And, while I know that I am not White, I also know that her Whiteness is part of me. This makes it difficult to apply ideas about ethnic and racial identity that include a period of rejecting White values as progress towards positive ethnic and racial identity.

Another difficulty identifying as Japanese American came from feeling that I didn't seem to fit in with those who were wholly Japanese in heritage any better than with those who were wholly White American. When I was in college, I attended some events at the Asian club. I don't know if the feeling I got of being an outsider and not really genuine came from other members or from within, but I remember feeling different, as if I didn't really belong. I didn't speak Japanese; I didn't seem to share the same experiences or have the same values and attitudes (or at least I didn't know it if I did); I didn't even know the Japanese names for the foods I ate and I felt like we were speaking about different things even when we did have similar experiences. I felt like I had to prove that I was truly Japanese and I knew for sure I couldn't succeed in that. Later, when other Asians would attribute my lack of Japanese language skills to my multiracial heritage and being "watered down" or "whitewashed", I wondered if I should tell them that one of the major contributors to my "lack" of Japanese cultural "authenticity" was not my multiraciality which they perceived as distinct from a shared Japanese American or Asian American experience, but was actually my father's camp experience and the cultural stripping that accompanied negotiating that racism, experiences that were actually central to the shared experience of being Japanese American, whether monoracial or multiracial.

Multiracial Japanese Americans self-identification is most strongly connected to being multiracial, American, and Japanese American, while Japanese and European American self-identification are less highly endorsed (Suyemoto 2004). Identity is not only an individual experience, but a social meaning related to how one is seen and treated by others (Khanna 2004; Suyemoto 2004). For example, Khanna found that multiracial Asian Americans' affiliations with Asian identity were most strongly shaped by racial categorization by others' perceptions of their phenotype, and by cultural exposure, and that part of the importance of cultural exposure was that it affected others' perceptions and experiences of belonging. Having identity that is validated by others is associated with more identity integration (less conflict and distance between two different racial identity referents) and greater self-concept 
clarity (Lou et al. 2011). Thus, it is the both/and that reflects the felt experience for multiracial Asian Americans, and the social validation of the both/and is important. However, that both/and experience can be challenged not only by the intergenerational legacy of the camps, but also by the unique positionality of multiracial Sansei. This was exemplified by Wendy, an interviewee who spoke about her experiences of marginalization from both White and Asian Americans in response to a question about her identity:

I looked different, [White] people would tell me, would always be asking me what I was, they would tell me I was exotic....I can remember this whole business about being different. It's such a core theme in my life. I was just being isolated and being different .... .

I did some work with the Asian American movement, different organizations, but I always felt a little bit of ambivalence about it because there was a lot of White bashing and there was a lot of essentialism going on, I thought. And there still continues to be a lot of essentialism about this Asian identity and a lot of assumptions about things that people have in common. Then I start feeling this sort of clandestine "Am I authentic enough? Am I going to be found out?" You know, that I have this White mother.

The ethnic and racial identity process of multiracial Sansei is problematized not only by experiences of racism and exclusion by the dominant White American group, such as the legacy of the camps, but also by experiences of discrimination and exclusion by the Japanese American group and by possible exclusion and rejection from either or both sides of their extended families (Root 1990). These issues not only complicate identity, but they affect mental health, as both multiracial identity conflict and racial discrimination are associated with distress and negative affect, and those who experience high conflict have greater negative effects of discrimination (Lou et al. 2011). The exclusion experienced by multiracial Sansei has echoes of both the White American racism that led to the mass incarceration and of the tensions described within the camps (especially around the loyalty questionnaire) between those seen as too American and those seen as too Japanese. Multiracial individuals experience less valuing of their White identity when other minorities are around (Wilton et al. 2013). However, the legacy of the camps could contribute to particular challenges, because the camp experience makes the stigma of being a racial minority more salient; consciousness of racial stigma or marginalization is related to also feeling less belonging in the presence of White people for multiracial individuals, and lower White identification (Wilton et al. 2013).

Multiracial Sansei may experience discrimination within the dominant White American community similar to that experienced by monoracial Sansei as a visible minority and similarly problematizing their affinity with an identification as American. However, unlike monoracial Sansei, multiracial White/Japanese Sansei may experience this discrimination from within their own White European American family members, as I described above. John remembered how his grandmother's prejudice not only affected him individually, but also affected his relations with his brother "She didn't like, or she still doesn't like, anybody who's non-White. So she was furious when my father married my mother ... when it would be Christmas time, she'd bring a Christmas present for my brother, but not for me, because she kept on accusing my mother of fooling around, 'cause she said I looked more Japanese than my brother." This internal-to-the-family discrimination makes it more challenging for multiracial Sansei to receive positive racial socialization within the family, leaving them without family guidance for preparing them for discrimination. For example, when I told my White mother about being chased home and called a "Jap", she responded that kids could be mean. While true, it offered little to prepare me to deal with similar racism that continued throughout my life after that date.

Furthermore, unlike monoracial Sansei, multiracial Sansei may also experience discrimination from within the Japanese American or Asian American communities because of their multiraciality. Several interview participants in addition to Wendy discussed exclusion or discrimination within the Japanese American community based on a number of issues such as names (if their last names were not Japanese), appearances, and the idea of racial purity. John noted that some multiracial 
Japanese Americans of his age and generation had enough Japanese heritage that they could have been imprisoned in the camps, but not "enough" to participate in some activities in his Japanese American community when he was growing up, which sometimes set blood quantum limits. Brian directly related his feelings of exclusion and discrimination as a multiracial Japanese American in the Japanese American community to the camp experience: “There was some blatant stuff like rules. You had to have a Japanese surname or you had to show a birth certificate. [to belong to Japanese American game leagues or be in the Cherry Blossom beauty contest] ... It pissed me off that if I wanted to [participate] I knew that there was somebody out there because of some rule structure that could say I couldn't, or give me grief about it ... it's kind of a matter of principle, and I think that relates directly back to the internment ... that there was power there to say you know you can't do this, and you can't do this, you can't go here, you can't go here, you're this, you're not this".

For multiracial Sansei, these experiences of discrimination from within the Japanese American community may complicate the development of a positive ethnic and racial identity and coming to terms with discrimination and racial politics from the dominant White European American, such as that exemplified in the camp experience. After the war, Sansei continued to prefer ethnic organizations (Kitano and Daniels 2000), and familial experience of the camps increased Sansei's expressed preference for interacting with Japanese Americans, rather than White Americans (Nagata 1990). However, experiences of discrimination within the Japanese American community may have hindered multiracial Sansei's access to or use of resources within their own ethnic group, including groups or events that were organized to discuss or address the effects or implications of the camps.

The identity development of multiracial Sansei may also differ from monoracial Sansei in relation to their negotiating the effects of racism and the dominance of the White European American culture. Many ethnic and racial identity models (see overview in Chang and Kwan 2009) propose a stage where individuals actively reject White European American culture, identity, and community and instead immerse themselves in their ethnic minority culture, and racial and ethnic community. This stage is often catalyzed by learning about or experiencing personal effects of discrimination; for Sansei, this stage may have been catalyzed by learning about the injustice and oppression of the camps. However, multiracial Sansei may not have had the option of immersing in the Japanese American or Asian American communities, as they experienced rejection from these communities. Laura reflected about learning more about the camps in college by stating:

My professor was talking about the camps as sort of a culmination of anti-Asian activity ...

[It] made me upset and mad and feel betrayed by my government and feel like an outsider. When I would learn more about these people who supposedly were good presidents or good people and suddenly I started seeing them as people who wouldn't have liked me if I'd been there at that point, and, and who were more like enemies to my family and stuff.

However, she also stated of her time in college: " ... there were people who are telling me "you're not a real Japanese American, you're not a real Asian American" or whatever. The experience of a stage of rejecting dominant White identity or values in response to learning about the camps as rooted in White interpersonal and governmental racism may also have been problematic. Laura later responded to a question regarding how the camp experience affected her ethnic and racial identity in ways that acknowledged her difference from monoracial Sansei: "I think that it's always complicated matters for me, that I have all these people who are White, who love me and who I love. You know, so that there was never this period where I could just sort of be comfortable in just hating White people. That was never a real healthy option for me, where for other people, it could potentially be a really comfortable place to be at".

\section{Reflections on Intergenerational Healing and Contributions to Racial Justice}

When I was in graduate school in the early 1990s, I began to ask questions that I'd never asked before. What does it mean to be Japanese American? What does it mean to be multiracial? Why was so little named in 
my family? What was the camp experience really like, and how did it affect my father and his family? Around this time, my father, my stepmother and I took a trip that included a pilgrimage to Topaz. There, I heard stories that I hadn't heard before and experienced what the environment was actually like, enabling an imagination of my father's experience.

After graduate school, I began to link my professional work with this questioning, by embarking on a research project exploring ethnic and racial identity in multiracial Japanese Americans. This was a healing process for me, enabling me to address some of the issues of transmission and racial exclusion and acceptance, through independent reading, my research conversations with other multiracial Japanese Americans, and through direct conversations with my father. This process helped me better find my place, understand my history, and understand how the concentration camp experience has shaped my family and myself. I think that this process was also a healing one for my father, as my (and my sister's) questions led him to reexamine his experiences and identification. Some time afterwards, he said to me that for decades after the camps, he hadn't thought of himself as Japanese and didn't want to think of himself that way; he didn't want to think about the camps or recognize the impact on his view of his ethnicity and development. But he said that now he does think of himself as Japanese American and could take some pride in this, and that this was partly a result of our questions and his desire for us to feel pride in ourselves and our heritage.

Through the intervening years, racial and intersectional justice have becoming increasingly central to my professional activities and integrated into my identity. And part of that integration has been an expansion of my ethnic and racial identities, from a sense of uncertainty of my own position ("my father is Japanese") to identifying as multiracial or Japanese American, to unifying multiracial Japanese American, and finally to identifying as a person of color, an Asian American, multiracial, and Japanese American. What the intersection of the camps and being multiracial made clear to me over time was the fact that the problem was not the war, or being Japanese American, or not fitting into the racial categories. The central problem was with the hierarchies of power and privilege that foster exclusion, discrimination, racism, and injustice. This recognition contributes to the pressing motivation that Japanese Americans, have an obligation to foster coalitions and work with other Asian Americans and people of color to work for racial justice.

Talking about the WWII mass incarceration and the Nisei and Sansei experience of being Japanese American in a society dominated by White European American views was part of healing for those involved (Miyoshi 1978). Breaking the silence and related trauma recovery were the primary benefits of the redress movement. Redress catalyzed familial and community intergenerational discussions, as reflected in Nagata and Cheng's (2003) findings that over 75\% of Nisei reported that redress increased their willingness to discuss the camp experience. Nagata and Takeshita (2002), note:

Intergenerational bonds strengthened [from redress], particularly between the second generation U.S. born (Nisei) Japanese Americans who had lived through the internment and their offspring, the third generation (Sansei). (p. 43)

Nagata and other authors also note that redress was catalyzed by Sansei (e.g., Nagata et al. 2015), perhaps as a means to negotiate the complexity of racial and ethnic identity development in the context of the camp's historical legacy of racism. During W.W.II., being Japanese American meant being alien and imprisoned. Redress built upon the civil rights and Asian American movements to offer a different narrative, of empowerment, perseverance, and unity, and an opportunity to rebuild trust in the U.S.

Intergenerational family conversations about the camp experience opened the door to the many ways in which this experience shaped the meaning of being Japanese American and ethnic and racial identity development in both Nisei and Sansei. Discussion of the camps helped Sansei place themselves within their communities, understanding the development of Japanese American community and identity within the historical and current dominant American context, thus contributing to addressing the issues discussed above that are related to racial acceptance and exclusion. Group and community conversations contributed to healing through sharing experiences and perspectives, exploring the broader historical context, understanding how the past influences the present and the future, and planning for how Japanese Americans may contribute in the future. These conversations not 
only validated familial conversations, but also explored how the long-term effects of the concentration camps were a community concern, rather than an experience idiosyncratic to a single individual or family.

The kinds of conversations I had with my father that contributed to strengthening his own positive racial and ethnic identity as Japanese American were therefore perhaps not specific to my being multiracial but more reflective of the Nisei-Sansei interactive experience more generally. However, some multiracial Sansei may have had less opportunity to participate in these dialogues with their parents or within the larger community. Familial communication for multiracial Sansei may have been blocked by more intense cultural or racial distancing, and community communication may have been blocked by exclusion within the Japanese American community towards multiracial individuals or by a lack of parental or personal connection to the Japanese American community. Nagata and Takeshita (2002) found that positive impacts of redress were stronger among Nisei with preference for other Japanese Americans, which may be less common among those Nisei who chose to outmarry. For me, the community of Japanese and Asian Americans that fostered a sense of connection and community post-redress for many Sansei was not open, given my experiences of exclusion there as a multiracial Asian American ${ }^{5}$. In addition, as expressed by some of our interview participants, some multiracial individuals may have felt that the exclusion they felt was actually maintained by the focus on the camps: that the focus on the camps was looking towards the past, not the future. Some of our interviewees in the late 1990s felt that the focus on the camps happened instead of a focus on issues such as the changing face of the Japanese American community characterized by increasing outmarriage and multiracial Japanese Americans, and so resulted in ignoring the marginalization of multiracial individuals. This raised the question then whether a focus on the camps was a backwards focus.

My answer then and now, twenty years later, is that it is not a backwards focus. We still have lessons to learn from the camp experience, from the intergenerational transmission of and healing processes from the associated trauma, and from the racial dynamics imposed upon and enacted within the Japanese American community during and following WWII. Simultaneously, I think this should be a both/and approach with issues of multiraciality, rather than an either/or; I believe that explicitly attending to the ways that multiraciality interacts with intergenerational processes of oppression and resistance adds unique contributions that are relevant today.

In 1993, Nakanishi argued that the camp experience should serve as a reason for maintaining a group identity as Japanese American and as the basis for developing a unique contribution to American society:

I also believe that to identify as a Japanese American is to recognize the distinctiveness and enduring impact of our shared collective experience of surviving through and gradually coming to terms with the internment ... We must come to see that the unique contribution which we as Japanese Americans can make to American society is not the adding of a so-called 'foreign' ingredient to the proverbial American melting pot, but instead to share and forever apply our distinct vantage points of this society and of this government, which are based on our unique internment experience ... To be a Japanese American, I believe, should mean that the internment remains at the forefront of our collective memory, and the basis of the most distinct contribution that we can make to this society. (Nakanishi 1993, pp. 30-31).

Nakanishi was not, I believe, calling for Japanese Americans to only contribute to Japanese Americans; he was instead calling for Japanese Americans to use their experiences with the camps to make a "distinct contribution" for justice, to remember the lived experience and the intergenerational legacies of extreme bigotry. Recent events emphasize the need for that contribution: Japanese

5 My experience as a multiracial Sansei is also shaped by being in the Northeast, where the populations of both Japanese Americans and multiracial Asian Americans are less numerous than on the west coast. 
Americans were central and necessary voices in resisting the targeting of Arab and Muslim Americans post 9/11, including calls for possible incarceration. The camp experience within our Japanese American community is one that helps us to understand and resist racism and discrimination, one that can offer Japanese Americans great influence in speaking truth to power, one that we can use to foster empathy, understanding, and motivation to challenge injustice (see, for example, Srikanth 2011 Constructing the Enemy).

The experiences of multiracial Sansei can bring a particular perspective to this contribution. Multiraciality and the legacy of the camps interact because the Japanese American multiracial experience is inherently related to the long-term impact of the camp experience. ${ }^{6}$ The camp experience is an example of institutionally and nationally sanctioned oppression that contributed to increased assimilation, which is a major contributor to outmarriage, and, of course, to multiracial children. Simultaneously, this assimilation and the increase of multiracial members within the Japanese American community threatened the unity and identity of the Japanese American community. Multiracial Sansei's experiences of exclusion and difference in the Japanese American and/or dominant communities echo the historical experience of exclusion and can be understood as a response to this perceived threat. These dynamics continue today. Although the Japanese American community has become more accepting of multiracial Japanese Americans ${ }^{7}$, the Asian American community more broadly continues to marginalize multiracial Asian Americans. For examples, Museus et al. (2016) found that their multiracial participants (which included 22 Asian Americans) experienced prejudice and discrimination characterized by racial essentialization, identity invalidation, imposition of racial identities, challenges to racial authenticity, pathologizing of the multiracial experience, and exclusion and marginalization from both White and Asian people/communities. Nadal et al. (2013) described discrimination experienced by multiracial people within their families that reflected many of the issues reflected in the personal narrative and interview examples above, including isolation, racial favoritism, questioning of authenticity, denial or identity, and negative feelings related to not learning about cultural heritage within the family. Suyemoto (2004) described how one third of her Japanese American White multiracial participants stated that they would identify most with a Native American-African American multiracial person rather than a monoracial White or Asian American person because of experiences of marginalization from these communities. My own experiences with Asian Americans who do not know me continues to be variable although primarily characterized by numerous microaggressive experiences of "othering", such as being told I do not "look" Asian American, being asked why I am at an Asian American event or why I teach Asian American Studies, being told I don't act "Asian enough," or being chided for "watering down" Asian pride. Multiracial Asian American students in my classes report to me that the term "twinkie" has replaced "banana", and it is frequently leveraged against them, along with multiple instances of discrimination or exclusion from other Asian Americans. The ways that Asian American communities internalize racial essentialization and border patrolling reflects the larger system of racism (Suyemoto and Dimas 2003). Explicit acknowledgement that multiracial Japanese or Asian Americans are not a "foreign" ingredient in the community, just as Japanese Americans were (and are) not a "foreign" ingredient in the larger American community could encourage an exploration not only of the meaning of race for Japanese and Asian Americans, but also how race and racism has been constructed throughout recent decades-a dialogue that could contribute to addressing internalized racism more broadly, not only related to the camp.

Including the experiences and voices of multiracial Japanese Americans in our analysis of the camps also enables us to consider questions related to more complex dynamics, resisting a simple "us" and "them" construction. This has the potential to increase our ability to engage intersectionality

6 My thanks to Kunya des Jardins and Pata Suyemoto for helping me to clarify this point.

7 Particularly on the west coast, which is the location of the majority of the population. 
(e.g., see Cole 2009) in our understanding of identities, resistance, and mental health by applying Cole's central questions for intersectional analysis to our analysis of the effects of the camps for Japanese Americans: Who is included within this category? What role does inequality play? Where are there similarities? The inclusion of these questions deepens our understanding of intergenerational legacies of oppression.

Furthermore, including an analysis of multiracial experiences in consideration of the camps enables us to open more complex questions about reciprocity in intergenerational negotiation and transmission of oppression and healing. My father experienced interpersonal, systemic, and government sanctioned racism; he was 13 when he was incarcerated behind barbed wire and 16 when he was released. From my perspective as a race scholar and psychologist, he responded to that experience by internalizing the racism, seeking to have "American" children, meaning White. But I am not White, and the multiple experiences of racism I brought to my interactions with him made it clear that his attempt at protection through internalization could not succeed. For me, being multiracial and having the intergenerational legacy of the extreme discrimination of the camps combined to create a central and visceral attention to the questions "Who is being excluded? Who has less voice, less power, less acceptance?" While I believe the camp experience itself catalyzes these questions and motivations, being multiracial encouraged me to consider how the ingroup and the outgroup are particularly complex and, themselves, create hierarchies—and to be aware that what I see (or think) is shaped as much or more by how I see as it is by what is "actually" there (Kinsley 1994). Being multiracial is associated with appreciating multiple viewpoints, accepting difference, and preferring not to belong to groups that exclude others (Suyemoto 2004); it is also associated with sensitivity to feeling like an outsider and with racial resistance, rejecting and critiquing the categorization and primacy of race, including education of themselves and others about race, racism, and stereotypes (Jackson 2010). These multiracially associated experiences were primary in opening intergenerational dialogue about race and challenging my father's internalization of racism, including his erroneous belief that outmarriage would be protective. Thus, there are ways in which my multiracial Japanese American experience exemplifies that intergenerational negotiation is not only one-way transmission, but a more complex cycle of reciprocal oppression and resistance.

At this moment in U.S. history, when racial and ethnic profiling for policing, immigration, and denial of rights, such as due process, are now integrated into our governmental policies and procedures, we can surely benefit from the combination of the deep felt intergenerationally lived awareness of injustice from the camps, and the experience of being "between" as a multiracial person with the associated skill in adopting multiple perspectives. To make the contribution Nakanishi envisions with honor and integrity, we who are seeking to resist the kind of groupthink that led to the camps must also look internally within our communities to more complex legacies of race, racialization, cultural stripping, and the ways that we may intergenerationally carry forward not only the resistance and resilience, but also, inadvertently, the tendencies to create exclusive or harmful boundaries (e.g., Suyemoto and Dimas 2003; Suyemoto and Donovan 2015). For Japanese Americans, the allure of the "model minority" and "honorary White" is a dangerous siren's call that the camp legacy might offer some protection from if, as Nakanishi entreats, we keep it "at the forefront of our collective memory." On the opposite side, the continued exclusion of multiracial individuals within Asian American communities is yet another way we internalize damaging racial dynamics and we, as Japanese Americans, might bring to bear our experiences with injustice to consider how we might better resist reifying exclusion and oppression. Furthermore, it is not only Japanese Americans or multiracial individuals, or multiracial Japanese Americans with intergenerational camp legacies who can access those perspectives; because we are all capable of imagination and empathy, we can all learn these intergenerational lessons of resistance and responsibility.

Author Contributions: Karen L. Suyemoto conceived and designed the study from which the interview quotes were taken. Interviews were conducted by Karen L. Suyemoto and Patricia Suyemoto.

Funding: This paper received no external funding. 
Acknowledgments: I thank the Sansei Legacy Project and Sean for inspiring this article. I also thank Grace Kim, Kunya des Jardins, and Patricia Suyemoto for their feedback that served to improve this article.

Conflicts of Interest: The author declares no conflict of interest.

\section{References}

Ancheta, Angelo N. 2006. Race, Rights, and the Asian American Experience. New Brunswick: Rutgers University Press. Austin, Allan W. 2007. Eastward Pioneers: Japanese American Resettlement during World War II and the Contested Meaning of Exile and Incarceration. Journal of American Ethnic History 26: 58-84.

Chang, Tai, and K. Karl Kwan. 2009. Asian American racial and ethnic identity. In Asian American Psychology: Current Perspectives. Edited by Nita Tewari and Alvin N. Alvarez. New York: Routledge/Taylor and Francis Group, pp. 113-33.

Chung, Ruth H. 2001. Gender, ethnicity, and acculturation in intergenerational conflict of Asian American college students. Cultural Diversity and Mental Health 7: 376-86. [CrossRef]

Cole, Elizabeth R. 2009. Intersectionality and Research in Psychology. American Psychologist 64: 170-80. [CrossRef] [PubMed]

Daniels, Roger. 1991. The conference keynote address: Relocation, redress, and the report: A historical appraisal. In Japanese Americans: From Relocation to Redress. Edited by Roger Daniels, Sandra C. Taylor and Harry HL Kitano. Seattle and Washington: University of Washington Press, pp. 3-9.

Gullickson, Aaron, and Ann Morning. 2011. Choosing race: Multiracial ancestry and identification. Social Science Research 40: 498-512. [CrossRef]

Hall, Edward T. 1976. Beyond Culture. Garden City: Anchor Press.

Hirabayashi, James. 2008. "Concentration Camp" or "Relocation Center"—What's in a Name? Discover Nikkei. Available online: http:/ /www.discovernikkei.org/en/journal/2008/4/24/enduring-communities/ (accessed on 13 June 2018).

Jackson, Kelly Faye. 2010. Living the multiracial experience: Shifting racial expressions, resisting race, and seeking community. Qualitative Social Work: Research and Practice 11: 42-60. [CrossRef]

Japanese American Citizen's League. 2015. Power of Words Handbook: A Guide to Language about Japanese Americans in World War II. Available online: https:/ /jacl.org/wordpress/wp-content/uploads/2015/08/ Power-of-Words-Rev.-Term.-Handbook.pdf (accessed on 13 June 2018).

Japanese American National Museum. 1994. Japanese American National Museum Quarterly. Los Angeles: Japanese American National Museum, vol. 9, pp. 11-16.

Japanese American National Museum. n.d. Terminology and the Japanese American Experience. Available online: http:/ / media.janm.org/projects/ec/pdf/EC-Terminology.pdf (accessed on 13 June 2018).

Khanna, Nikki. 2004. The Role of Reflected Appraisals in Racial Identity: The Case of Multiracial Asians. Social Psychology Quarterly 67: 115-31. [CrossRef]

Kim, Bryan SK. 2009. Acculturation and enculturation of Asian Americans: A primer. In Asian American Psychology: Current Perspectives. Edited by Nita Tewari and Alvin N. Alvarez. New York: Routledge/Taylor and Francis Group, pp. 97-112.

Kinsley, Claire Huang. 1994. Questions people have asked me. Questions I have asked myself. In Miscegenation Blues: Voices of Mixed Race Women. Edited by Carol Camper. Toronto: Sister Vision, pp. 113-32.

Kitano, Harry HL. 1993. Generations and Identity: The Japanese American. Needham Heights: Ginn Press.

Kitano, Harry HL, and Roger Daniels. 2000. Asian Americans: Emerging Minorities, 3rd ed. Upper Saddle River: Prentice Hall.

Lee, Cynthia. 2015. Debate over words to describe Japanese American incarceration lingers. UCLA Newsroom: Nation, World, and Society. Available online: http://newsroom.ucla.edu/stories/debate-over-words-todescribe-japanese-american-incarceration-lingers (accessed on 13 June 2018).

Lin, Nancy J., and Karen L. Suyemoto. 2016. "So You, My children, can have a better life": A Cambodian American perspective on the phenomenology of intergenerational communication about trauma. Journal of Aggression, Maltreatment and Trauma 25: 400-20. [CrossRef]

Lou, Evelina, Richard N. Lalonde, and Carlos Wilson. 2011. Examining a multidimensional framework of racial identity across different biracial groups. Asian American Journal of Psychology 2: 79-90. [CrossRef] 
Markus, Hazel Rose. 2008. Pride, Prejudice, and Ambivalence: Toward A Unified Theory of Race and Ethnicity. American Psychologist 63: 651-70. [CrossRef] [PubMed]

Mass, Amy Iwasaki. 1991. Psychological effects of the camps on Japanese Americans. In Japanese Americans: From relocation to redress. Edited by Roger Daniels, Sandra C. Taylor and Harry H.L. Kitano. Seattle: University of Washington Press, pp. 159-62.

Mass, Amy Iwasaki. 1992. Interracial Japanese Americans: The best of both worlds or the end of the Japanese American community. In Racially Mixed People in America. Edited by Maria P. P. Root. Newbury Park: Sage, pp. 265-79.

Maykovich, Minako K. 1972. Japanese American Identity Dilemma. Tokyo: Waseda University Press.

Miller, Donald E., and Lorna Touryan Miller. 1993. Survivors: An Oral History of the Armenian Genocide. Berkeley: University of California Press.

Miyoshi, Nobu. 1978. Identity Crisis of the Sansei and the Concentration Camp; (Grant report No. I R13 MH25655-01). Bethesda: National Institute of Mental Health.

Morishima, James K. 1982. Testimony of James K. Morishima, Ph.D. on behalf of the American Psychological Association before the Commission on Wartime Relocation and Internment of Civilians. Journal of the Asian American Psychological Association 7: 6-12.

Museus, Samuel D., Susan A. Lambe Sariñana, April L. Yee, and Thomas E. Robinson. 2016. A Qualitative Analysis of Multiracial Students' Experiences with Prejudice and Discrimination in College. Journal of College Student Development 57: 680-97. [CrossRef]

Nadal, Kevin L., Julie Sriken, Kristin C. Davidoff, Yinglee Wong, and Kathryn McLean. 2013. Microaggressions within Families: Experiences of Multiracial People. Family Relations 62: 190-201. [CrossRef]

Nagata, Donna K. 1990. The Japanese American internment: Exploring the transgenerational consequences of traumatic stress. Journal of Traumatic Stress 3: 47-69. [CrossRef]

Nagata, Donna K. 1991. Transgenerational impact of the Japanese-American internment: Clinical issues in working with children of former internees. Psychotherapy 28: 121-28. [CrossRef]

Nagata, Donna K. 1993. Legacy of Injustice: Exploring the Cross-Generational Impact of the Japanese American Internment. New York: Plenum Press.

Nagata, Donna K. 1998. Internment and intergenerational relations. In Handbook of Asian American Psychology. Edited by Lee C. Lee and Nolan WS Zane. Thousand Oaks: Sage, pp. 433-56.

Nagata, Donna K., and Wendy J.Y. Cheng. 2003. Intergenerational communication of race-related trauma by Japanese American former internees. American Journal of Orthopsychiatry 73: 266-78. [CrossRef] [PubMed]

Nagata, Donna K., and Yuzuru J. Takeshita. 2002. Psychological reactions to redress: Diversity among Japanese Americans interned during World War II. Cultural Diversity and Ethnic Minority Psychology 8: 41-59. [CrossRef] [PubMed]

Nagata, Donna K., and Garyn K. Tsuru. 2007. Psychosocial correlates of self-reported coping among Japanese Americans interned during World War II. American Journal of Orthopsychiatry 77: 221-30. [CrossRef] [PubMed]

Nagata, Donna K., Jackie H.J. Kim, and Teresa U. Nguyen. 2015. Processing Cultural Trauma: Intergenerational Effects of the Japanese American Incarceration. Journal of Social Issues 71: 356-70. [CrossRef]

Nakanishi, Don T. 1993. Surviving democracy's "mistake": Japanese Americans and the enduring legacy of the Executive Order 9066. Amerasia Journal 19: 7-35. [CrossRef]

“Nisei”. 2013. Densho Encyclopedia. Available online: https:// encyclopedia.densho.org/Nisei/ (accessed on 19 July 2018).

O'Brien, David J., and Stephen S. Fugita. 1991. The Japanese American Experience. Bloomington: Indiana University Press. Omi, Michael, and Howard Winant. 1994. Racial formation in the United States, 2nd ed. New York: Routledge.

Pennebaker, James W., Steven D. Barger, and John Tiebout. 1989. Disclosure of traumas and health among Holocaust survivors. Psychosomatic Medicine 51: 577-89. [CrossRef] [PubMed]

Phinney, Jean S., and Anthony D. Ong. 2007. Conceptualization and measurement of ethnic identity: Current status and future directions. Journal of Counseling Psychology 54: 271-81. [CrossRef]

Poston, W.S. Carlos. 1990. The biracial identity development model: A needed addition. Journal of Counseling and Development 69: 152-55. [CrossRef]

Root, Maria P.P. 1990. Resolving "other" status: Identity development of biracial individuals. Women and Therapy 9: 185-205. [CrossRef] 
Schumacher-Matos, Edward, and Lori Grisham. 2012. Euphemisms, Concentration Camps and the Japanese Internment. NPR Ombudsman. Available online: https:/ / www.npr.org/sections/ombudsman/2012/02/10/ 146691773/euphemisms-concentration-camps-and-the-japanese-internment (accessed on 13 June 2018).

Shih, Margaret, Courtney Bonam, Diana Sanchez, and Courtney Peck. 2007. The social construction of race: Biracial identity and vulnerability to stereotypes. Cultural Diversity and Ethnic Minority Psychology 13: 125-33. [CrossRef] [PubMed]

Smedley, Audrey, and Brian D. Smedley. 2005. Race as biology is fiction, racism as a social problem is real: Anthropological and historical perspectives on the social construction of race. American Psychologist 60: 16-26. [CrossRef] [PubMed]

Srikanth, Rajini. 2011. Constructing the Enemy: Empathy/Antipathy in U.S. Literature and Law. Philadelphia: Temple University Press.

Stephan, Cookie White. 1992. Mixed-heritage individuals: Ethnic identity and trait characteristics. In Racially Mixed People in America. Edited by Maria P. P. Root. Newbury Park: Sage.

Sue, Derald Wing, and David Sue. 2015. Counseling the Culturally Diverse: Theory and Practice. New York: Wiley.

Sue, Derald Wing, Jennifer Bucceri, Annie I. Lin, Kevin L. Nadal, and Gina C. Torino. 2007. Racial microaggressions and the Asian American experience. Cultural Diversity and Ethnic Minority Psychology 13: 72-81. [CrossRef] [PubMed]

Suyemoto, Karen L. 2002. Redefining "Asian American" identity: Reflections on differentiating ethnic and racial identities for Asian American individuals and communities. In Asian Americans: Vulnerable Populations, model Interventions, and Clarifying Agendas. Edited by Lin Zhan. Boston: Jones and Bartlett, pp. 195-231.

Suyemoto, Karen L. 2004. Racial/Ethnic Identities and related attributed experiences of multiracial Japanese European Americans. Journal of Multicultural Counseling and Development 32: 206-21. [CrossRef]

Suyemoto, Karen L., and Juanita M. Dimas. 2003. To be included in the multicultural discussion: Check one box only. In Culturally Diverse Mental Health: The Challenges of Research and Resistance. Edited by Jeffrey S. Mio and Gayle Y. Iwamasa. New York: Brunner-Routledge, pp. 55-81.

Suyemoto, Karen L., and Roxanne A. Donovan. 2015. Exploring intersections of privilege and oppression for Black and Asian immigrant and US born women: Reaching across the imposed divide. In Gendered Journeys: Women, Migration and Feminist Psychology. Edited by Oliva M. Espín and Andrea L. Dottolo. New York: Palgrave Macmillan, pp. 54-75. [CrossRef]

Takaki, Ronald. 1998. Strangers from a Different Shore: A History of Asian Americans. Boston: Back Bay Books.

Ting-Toomey, Stella. 1989. Intergroup communication and simulation in low- and high-context cultures. In Communication and simulation: From two fields to one theme. Edited by David Crockall and Danny Saunders. Philadelphia: Multilingual Matters, Ltd., pp. 169-76.

Tomine, Satsuki Ina. 1991. Counseling Japanese Americans: From internment to reparation. In Multicultural Issues in Counseling: New Approaches to Diversity. Edited by Courtland C. Lee and Bernard L. Richardson. Alexandria: American Association for Counseling and Development.

Tsuda, Takeyuki. 2014. 'I'm American, not Japanese!': The struggle for racial citizenship among later-generation Japanese Americans. Ethnic and Racial Studies 37: 405-24. [CrossRef]

Uba, Laura. 1994. Asian Americans: Personality Patterns, Idnetity, and Mental Health. New York: Guilford Press.

Wilton, Leigh S., Diana T. Sanchez, and Julie A. Garcia. 2013. The stigma of privilege: Racial identity and stigma consciousness among biracial individuals. Race and Social Problems 5: 41-56. [CrossRef]

(C) 2018 by the author. Licensee MDPI, Basel, Switzerland. This article is an open access article distributed under the terms and conditions of the Creative Commons Attribution (CC BY) license (http://creativecommons.org/licenses/by/4.0/). 